\title{
FROM SYMBOLISM TO METAPHOR IN ARCHITECTURE
}

\section{Rimantas BUIVYDAS}

When a decision on providing one of the journal issues focusing on historical and contemporary representations of symbolism in architecture was taken, as a guest editor, I had no reservations about the importance of this phenomenon neither in the past nor these days, though many things in this respect have shifted in the practice of contemporary architects. When one thinks about symbolism in architecture and the historical development of this old phenomenon, s/he realizes that almost everything in this field - from general things to details - not only embodies and expresses various existential ideas, but also, as if from another side of reality, narrates, teaches, inspires, warns and, in one way or another, appeals to human consciousness, feelings and affects his/her way of life. In the objects permeated by symbolism, everything, including their structure and fragments, shapes of geometrical forms, the number of elements, proportional relations, building material, colours, lights and symbolical meanings that they convey, to a certain degree, contains human knowledge about sacred ideas related to the essence of human life. Through architecture, the nature of symbols is revealed, which is to be a peculiar mediator between the ideal and material and, at the same time, to be a form of communication that enables a human being to feel and comprehend the principle and meaning of an all-enveloping connection.

Various scholarly sources discussing the issues of symbolism and metaphors in architecture usually are mostly focused on research into historical past the first and foremost on architectural structures of a sacred character. The existence of symbolism in such architectural objects has never been questioned, and this is for good reasons. However, contemporary architecture containing some relations to symbolism is far less analyzed from this perspective. Certainly, one can understand that contemporary architecture has far less bonds to symbolism in its pure form while on the other hand Modernism that became dominating in the architecture of the last century neglected these aspects of architecture and even called for a kind of taboo on many older traditions of architectural creation.

Though not many contemporary architects attempt to integrate old archaic meanings of symbols in their works or to provide them with a visual metaphoric character, some of the practitioners in the field find appropriate to approach their structures from a semantic point of view and use certain symbols accordingly. They even feel a need for emphasizing spiritual aspects of their structures, their suggestiveness and an individual character as well as communicative aspects of their expressivity. The authors who were inclined to doubt that architecture should only serve specific pragmatic functions or some abstractions perhaps intuitively sought arguments in the same way as renowned cultural historian Johan Huizinga did when he was reflecting upon symbolic reasoning. According to Huizinga, symbolic thinking provides the vertigo of ideas and the pre-intellectual unity of identity of things and softens thinking based exclusively on the reason that, according to him, "elevates the feeling of life to its highest point".

Symbolism that was considered an inseparable part of all creation and architecture in particular is a phenomenon that should be looked upon today as a meaningful and resourceful component of architectural creation. On the other hand, research into architectural heritage and the historical development of architecture can hardly be adequate without a focus on the traditions of architectural symbolism. It is of utmost importance to pursue research in this direction as complex activity involving the aspects of interdisciplinary studies and drawing on resources of many scholarly fields.

As a guest editor of this issue, I would like to extend my sincere thanks to the authors who responded to a call for papers: professor J. Krzysztof Lenartowicz (Cracow), Dr Alenka Fikfak (Lubljana), Dr Christian Suau (Glasgow), Dr Carmelo Zappulla (Barcelona), architect Saulius Gecas (Rome), Dr Linas Krugelis (Vilnius) and doctoral student Martynas Mankus (Vilnius). 